\title{
Isolation, identification and increasing importance of 'free-living' amoebae causing human disease
}

\author{
ZSUZSANNA SZÉNÁSI, T. ENDO*, K. YAGITA* and ERZSÉBET NAGY \\ Department of Clinical Microbiology, Albert Szent-Györgyi Medical University, POB 482, H-6701 Szeged, \\ Hungary and ${ }^{*}$ Department of Parasitology, National Institute of Health, Tokyo, Japan
}

\begin{abstract}
Amphizoic small amoebic protozoa are capable of existing both in 'free-living' and in 'parasitic' form depending on the actual conditions. Two genera (Naegleria and Acanthamoeba) have become recognised as opportunist human parasites. Since the first description in 1965 of a lethal case of primary amoebic meningoencephalitis (PAM) caused by Naegleria, many more (mostly lethal) cases have been reported, while granulomatous amoebic encephalitis (GAE), as well as eye (keratinitis, conjunctivitis, etc.), ear, nose, skin and internal organ infections caused by Acanthamoeba have also occurred in rapidly increasing numbers. Both pathogenic and non-pathogenic species of Naegleria and Acanthamoeba are found worldwide in water, soil and dust, where they provide a potential source of infection. Successful differential diagnosis and appropriate (specific) therapy depends on precise laboratory identification of the 'free-living' amoebae. In most cases, isolation from the environment can be achieved, but identification and differentiation of the pathogenic and non-pathogenic strains is not easy. The methods presently available do not fulfil completely the requirements for specificity, sensitivity and reliability. Morphological criteria are inadequate, while thermophilic character, $\mathrm{pH}$ dependency and even virulence in infected mice, are not unambiguous features of pathogenicity of the different strains. More promising are molecular methods, such as restriction endonuclease digestion of whole-cell DNA or mitochondrial DNA, as well as iso-enzyme profile analysis after iso-electric focusing and staining for acid phosphatase and propionyl esterase activity. Use of appropriate monoclonal antibodies has also yielded promising results in the differentiation of human pathogenic and non-pathogenic strains. However, quicker, simpler, more specific and reliable methods are still highly desirable. The significance of endosymbiosis (especially with Legionella strains) is not well understood. The results of a systematic survey in Hungary for the isolation and identification of 'free-living' amoebae, including an investigation of the Hungarian amoebic fauna, the isolation of possibly pathogenic Naegleria strains and of some Acanthamoeba strains from eye diseases, as well as the finding of a case of endosymbiosis, are also reported here.
\end{abstract}

\section{Introduction}

Protozoa causing human diseases can be divided into those that have a life cycle with vector-mediated transmission to the human host (e.g., Plasmodium and Trypanosoma spp.), and those that are transmitted directly between human hosts (e.g., Entamoeba histolytica and Giardia lamblia). Another group of the protozoa that cause infections of man is formed by the amphizoic small amoebae belonging to the genera Naegleria and Acanthamoeba. The term 'amphizoic' was suggested by Page [1] for protozoa that are capable

Received 18 March 1997; accepted 3 June 1997.

Corresponding author: Dr Z. Szénási. of being either free-living or parasitic, regardless of which is the primary mode of existence [2]. Free-living amoebae belonging to the genera Naegleria and Acanthamoeba can be pathogenic to man in their parasitic form. Thus, the expression 'amoebosis', reserved previously for diseases caused by $E$. histolytica, has to be extended to those diseases caused by free-living amoebae. Naegleria is the aetiological agent of fulminant primary amoebic meningoencephalitis (PAM), whereas Acanthamoeba can produce chronic and acute granulomatous amoebic encephalitis (GAE) in man [3]. Furthermore, several different types of infections have been associated with Acanthamoeba, including some internal organ, eye, ear, skin and nasal infections $[2,4]$. 
Both pathogenic and non-pathogenic species of Naegleria and Acanthamoeba are found worldwide in water, soil and dust [3]. Lakes used for bathing may receive thermal discharges containing pathogenic free-living amoebae, and may represent a dangerous source of infection for man. However, in practice these organisms can be found everywhere: in the most diverse forms of natural waters (lakes, rivers, brooks, brackish waters), springs (including hot springs), swimming pools (even in pools treated 'adequately'), industrial cooling water, heating ventilation and airconditioning units, soil, dust and oceanic sediment, including soil and water from the Antarctic; they have been isolated even from domestic tap water, from bottled mineral waters and contact lens cleaning and storing liquids [5-13]. They have also been isolated from the human cornea, skin, lung and central nervous system $[4-6,8-12,14,15]$.

Identification of the free-living amoebae is not wellresolved, although a precise distinction between the pathogenic and non-pathogenic strains would be the only reasonable and acceptable base for differential diagnosis and specific treatment in the case of visionthreatening or sometimes lethal human diseases [3, 5, 6, 16-22]. Morphological criteria are inadequate for the distinction of pathogenic and non-pathogenic strains $[5,6,20,23]$. Differences in antigenic determinants have been found between pathogenic and non-pathogenic Naegleria strains [7, 20], while determination of the iso-enzyme profile by iso-electric focusing and analysis of mitochondrial or whole-cell DNA profiles also seem to be promising $[5,6,21,22$, 24-26].

In Hungary, the first two cases of human disease caused by free-living amoebae were reported by this Department in 1985 and 1988 [7, 14]. Since then, an additional case was reported in 1995 [6]. Subsequently, a systematic co-operative study was organised to isolate, identify and study the possible pathogenicity of the free-living amoebic flora in Hungary, with special reference to sites of human recreation, such as natural waters, hot springs and swimming pools. The first results and conclusions from this programme $[6,27]$ are also included in this review.

\section{Naegleria fowleri in the environment and in human disease}

PAM is a rare, but rapidly fatal, disease of the central nervous system of man, leading to death within a week. It is caused by the free-living amoebo-flagellate $N$. fowleri [28, 29]. Sparagano and co-workers state that, among the members of the genus Naegleria, only $N$. fowleri is pathogenic for man and produces an acute and fatal meningoencephalitis [20]. PAM is a fulminant neurological disease of healthy young persons with a recent history of contact with recreational water during swimming, bathing, water skiing or boating in fresh or brackish waters (lakes, rivers, ponds). The entry portal of $N$. fowleri is the olfactory neuroepithelium [30]. The disease has a sudden onset and a fulminant course associated with a diffuse haemorrhagic necrotising meningoencephalitis [31]. Since 1965, when this disease was first described in Australia [32], a number of cases have been reported worldwide $[3,16,17,19$, $20,29,33,34]$.

The pathogenic potential of Naegleria strains has been tested in mice by nasal instillation of amoebae [3], and it has been found that virulent strains from human patients kill mice rapidly [34]. In order to cause fatal PAM, Naegleria must be able to multiply in the host and has to survive the fever caused by this infection. Griffin [34] reported a test showing that temperature tolerance is related to virulence. Two distinct groups of Naegleria strains were obtained. The strains from fatal human infections grew well above the temperature of the highest fever (as high as $42^{\circ} \mathrm{C}$ ), while nonpathogenic amoebae did not grow above normal human temperatures. Griffin stated that, for examining the pathogenicity of Naegleria isolates, the temperature test was more useful than tests of virulence in mice, probably because susceptible strains of mice still differ somewhat in their susceptibility to different Naegleria strains. Other factors may also contribute, but their importance is unknown [34].

The pathogenic $N$. fowleri is ubiquitous, but most strains are isolated from naturally warm and artificially heated aquatic environments $[3,16,29,35-38]$. Since almost all human infections have occurred during hot weather and after swimming in warm water, a definite relationship to thermal pollution is suggested [34]. Although elevated temperature is generally associated with increased occurrence of $N$. fowleri, the actual thermal conditions that contribute to the induction of pathogenic strains of this amoeba are not understood completely [29]. Tyndall et al. [33] examined a new reactor cooling lake and found that the concentrations of thermophilic amoebae and thermophilic Naegleria spp. increased by as much as five orders of magnitude, compared with source water and sediment samples, in samples obtained at a temperature of $40^{\circ} \mathrm{C}$ during periods of thermal additions. Pathogenic $N$. fowleri increased by as much as two orders of magnitude. After cessation of thermal additions, concentrations of amoebae returned to the original pre-thermal perturbation levels within 30-60 days. Concentrations of thermophilic amoebae and thermophilic Naegleria spp. showed a significant correlation with temperature and conductivity [33]. The data of Sykora et al. [16] suggest that the optimum temperature for pathogenic Naegleria strains in heated effluents is $27-35^{\circ} \mathrm{C}$. Although their occurrence was related to elevated temperatures, no significant correlation was found for other biological parameters. However, most non-pathogenic Naegleria 
isolates were also obtained from discharges at elevated temperatures, and the isolation and identification of all Naegleria strains (either pathogenic or non-pathogenic) was based on thermal separation at $45^{\circ} \mathrm{C}$. De Jonckheere et al. [39] also found non-pathogenic $N$. fowleri in a thermally polluted canal by indirect immunofluorescence analyses of heterogenous populations that grew at $42^{\circ} \mathrm{C}$. They suggested that, under certain conditions, non-pathogenic strains may undergo physiological changes, on the basis of which they may become pathogenic. It should be mentioned that $N$. australiensis is thermophilic up to $42^{\circ} \mathrm{C}$ and pathogenic to experimental animals, but has not, so far, been identified in man, while $N$. andersoni (thermophilic up to $40^{\circ} \mathrm{C}$ ) is non-pathogenic. In addition, $N$. lovaniensis, like $N$. fowleri, grows up to $45^{\circ} \mathrm{C}$, but is non-pathogenic to man and experimental animals [19]. Considering these data, incubation of samples at $45^{\circ} \mathrm{C}$ cannot be considered as 'selective' for pathogenic $N$. fowleri from environmental samples [3]. Although this is not a strict rule, the presence of thermophilic (but, so far, non-pathogenic to man or experimental animals) Naegleria spp. in the water should be considered simply as an indication that the conditions are suitable for the growth of pathogenic $N$. fowleri [19]. To make the picture more complicated, pathogenic Naegleria strains have been found also in water at a relatively low temperature. Thus a pathogenic isolate was obtained from water at a temperature of only $16^{\circ} \mathrm{C}$ [40], while Wellings et al. [41] isolated pathogenic $N$. fowleri from bottom sediments when the water temperature was no more than $12^{\circ} \mathrm{C}$. Sykora et al. [16] supposed that the pathogenic amoebae developed in the cooling water when the temperature was higher and somehow survived the change in the environment.

\section{Identification of $\boldsymbol{N}$. fowleri}

At least five species of amoebae in the genus Naegleria have been isolated from aquatic habitats. Thus, it is important that pathogenic and non-pathogenic species are identified accurately in environmental surveys [29]. As Sparagano [20] states: 'For environmental monitoring in a preventive objective, we need to distinguish pathogenic $N$. fowleri from non-pathogenic Naegleria spp. in water samples and to be sure to identify the three forms of the amoeba (cysts, trophozoites, and flagellates) .... identification techniques have to be specific, sensitive and rapid to differentiate $N$. fowleri encephalitis from Acanthamoeba, viral, or bacterial encephalitis'. However, despite general agreement that pathogenic and non-pathogenic species should be identified accurately and rapidly for medical diagnosis, this goal is far from being achieved. The lack of distinguishing morphological criteria, the absence of a strict dependency on temperature, and the ineffectiveness of the $\mathrm{pH}$ in predicting the survival and virulence of $N$. fowleri at a range of $2.1-8.15$ [16] combine to make a great demand for the use of more fastidious techniques [42].

\section{Restriction endonuclease digestion of whole-cell $D N A$}

Characterisation of Naegleria spp. by the use of restriction endonuclease digestion of whole-cell DNA deserves special attention as a possible reliable method for distinction [29, 43, 44]. In the study by Huizinga et al. [29], a newly created cooling reservoir (Clinton Lake, IL, USA) was surveyed for Naegleria spp. before and after thermal additions from a nuclear power plant. It was found that the DNA of $N$. fowleri isolated from Clinton Lake and digested with $B g l \mathrm{II}, E c o$ RI, and HindIII restriction endonucleases, showed DNA restriction fragment length profiles (RFLPs) that were homologous with $N$. fowleri reference strain Lee isolated from a human case of PAM acquired in West Virginia, but showed major differences compared with the patterns of the other reference strains, $N$. gruberi and $N$. australiensis. This provided strong evidence for the genetic homology of the two $N$. fowleri strains isolated, one from the southern and one from the northern areas of the USA [29]. In contrast, De Jonckheere [18] found a difference between strains from Australia and Europe with restriction enzyme analysis of whole-cell DNA. On the basis of RFLPs, a subtype of the Australian type has been found in New Zealand, whereas different types, related to either the European type or the Australian type, have been detected in the USA. Recently, the isolation of $N$. fowleri from the environment in Japan was reported by De Jonckheere et al. [19]. When the RFLPs of the Japanese isolates were compared with those of $N$. fowleri strains from other geographic areas, the RFLPs of the Japanese isolates were found to be related most closely to the strains found in Oceania and most distantly to the European strains. This finding serves as additional evidence of the gradual differentiation of $N$. fowleri with increasing geographical distance. However, it does not settle the question as to whether the $N$. fowleri species originated from the American continent, as proposed originally by De Jonckheere and colleagues $[17,18]$. Nevertheless, the RFLP assay seems to provide an additional useful method for the characterisation of $N$. fowleri isolates. Together with other biological and morphological identification methods, it may allow more precise epidemiological investigations to be performed whenever cases of PAM occur.

\section{Agarose iso-electric focusing and staining for acid phosphatase and propionyl esterase activity}

For the specific identification of water-soluble protein extracts from axenically growing Naegleria spp., De Jonckheere et al. [19, 45] separated the proteins (obtained from isolates from different geothermal and industrial waters) by agarose iso-electric focusing on 
$\mathrm{pH}$ 3.5-10 gradient gels and stained for acid phosphatase (AP) and propionyl esterase (PE) activity. The banding patterns were compared with those obtained for Naegleria reference strains run on the same gel. The AP patterns were identical for $N$. fowleri isolates of different geographical origin, and were only slightly different from the $N$. lovaniensis pattern. However, with the PE patterns, $N$. lovaniensis was differentiated easily from $N$. fowleri, while only small differences in banding were seen among $N$. fowleri isolates of different geographical origin. The PE isoenzyme pattern of the Japanese $N$. fowleri isolates corresponds to the $N$. fowleri reference strains from Australia [19]. Tyndall et al. [33] used iso-enzyme profiles as an additional measure for speciating Naegleria isolates. After electrophoresis on an acrylamide $7.5 \%$ gel, the iso-enzyme patterns of pathogenic Naegleria spp. isolated from a new reactor cooling lake in Georgia, USA, were identical to the patterns of $N$. fowleri isolates from other sites in the USA and Belgium, but differed from those of $N$. lovaniensis [33]. Thus, it seems that no (or only very slight) differences in PE banding patterns between $N$. fowleri isolates from different continents can be discovered when the proteins are separated by iso-electric focusing [19].

\section{Use of monoclonal antibodies}

An immunological approach with monoclonal antibodies (MAbs) appears to be a promising tool for identification of Naegleria spp. Preliminary results for trophozoite forms have been reported [31, 46]. Visvesvara et al. [46] described the successful production of MAbs to $N$. fowleri. The MAbs reacted intensely with strains of $N$. fowleri originating from different geographical areas, but showed no reactivity with four other species of Naegleria, i.e., N. gruberi, $N$. jadini, $N$. lovaniensis and $N$. australiensis, or a strain of Acanthamoeba castellanii. It was also shown that these MAbs could be used successfully to identify trophozoites of $N$. fowleri in brain sections of patients who died of PAM, and also in the brain sections of mice that were infected experimentally with the HBWS-1 strain of $N$. fowleri. However, these MAbs did not cross-react with amoebae in brain sections from patients who died of GAE caused by $A$. castellanii. Because of their specificity, these MAbs can be used successfully for the differential diagnosis of PAM infections retrospectively [46]. Other results have also supported the diagnostic potential of $N$. fowleri-specific MAbs and demonstrated their ability to differentiate at post-mortem examination between Acanthamoeba and Naegleria spp. in a case of granulomatous amoebic encephalitis [31]. Sparagano et al. [20] produced two MAbs that reacted with $N$. fowleri trophozoite, cysts, or flagellate forms, but not with $N$. lovaniensis or other Naegleria spp. MAbs can be powerful tools, not only for clinical diagnosis, but also for environment control [20].
An important argument for the use of MAbs has been highlighted by Visvesvara et al. [46], who state that, in the absence of any clear-cut morphological differences between $N$. fowleri and other Naegleria spp., iso-enzyme analysis or animal pathogenicity tests should be performed to differentiate pathogenic $N$. fowleri from other Naegleria spp. Both of these procedures require the growth of large numbers of organisms, which is not only time-consuming but expensive. However, with species-specific MAbs that react only with $N$. fowleri, even very small numbers of $N$. fowleri amoebae can be identified quickly.

\section{Acanthamoeba in the environment and in human disease}

Members of the genus Acanthamoeba are the commonest amoebae in fresh water and soil. Dry cysts can survive for several years and are isolated regularly from natural waters, inadequately (and adequately!) treated swimming pools, soil, sewage, freshwater fish, brackish water, ocean sediments, dust, air and even bottled mineral water, or contact lens cleaning and soaking solutions [6-13, 15, 23, 27, 4762]. This normally 'free-living' organism occurs occasionally as an opportunist parasite of man [63]. Acanthamoeba may occur as a commensal in the nasopharynx of apparently healthy normal individuals [64] and in patients with possible virus infection, and is found not infrequently in tissue cultures used for virus isolation from nasal swabs [64]. Their significance seems to be increasing rapidly: Acanthamoeba spp. have been reported from keratitis, corneal ulcers, the central nervous system (CNS), the genitourinary tract and many other sites of the human body [8-11, $23,51-54,63,65-67]$. One of the aetiological agents of GAE is Acanthamoeba spp. [30]. The neurological infection is usually manifested with a subacute-tochronic illness, with signs of increased intracranial pressure and focal neurological deficit because of granulomatous brain lesions [31]. The penetration of the amoebae into the CNS is probably by haematogenous spread from a primary focus in the lower respiratory tract, skin or open wounds, but the amoebic trophozoites or cysts can reach the CNS directly through the olfactory neuroepithelium [30, 42]. GAE should be differentiated from brain abscesses produced by $E$. histolytica, and from PAM produced by $N$. fowleri and characterised by an acute, fulminant neurological disease mostly in healthy young individuals [30]. In contrast, various Acanthamoeba spp. cause a subacute-to-chronic GAE, usually in immunocompromised patients including those with AIDS [42, 68], with 'not-yet-understood immunological deficiencies' [30], or 'debilitated individuals with no exposure to contaminated water' $[42,68]$. Tuberculosis, fungal infection or cerebral cysticercosis should be considered in the differential diagnosis $[30,42]$. A number of studies emphasise the need to 
consider acanthamoebic infection in the differential diagnosis of eye infections that fail to respond to antibacterial, antifungal or antiviral therapy (especially in those patients who wear contact lenses) $[3,6,12$, $16-19,29,34,39-41,43-45,52,55,56,69,70]$. These infections are often a result of direct eye exposure to contaminated materials or solutions (e.g., contact lens soaking and cleaning fluids); however, commensal bacteria on the eyelids, conjunctiva and tear film may have an additional role in the pathogenesis of Acanthamoeba keratitis [13, 15, 51, 55]. The clarification of the pathogenic role of Acanthamoeba spp. (considered until now as simple commensals) in some other diseases waits for further urgently required detailed studies.

\section{Identification of Acanthamoeba}

The taxonomy of the small amoeba species is not well established. Consequently, little is known about the genetic relationships between pathogenic and nonpathogenic strains of Acanthamoeba. Several studies report on the analysis of mitochondrial DNA (mtDNA) variation in members of the genus Acanthamoeba as an aid in taxonomy [21, 24-26, 71]. This method has proved to be a useful approach to studying evolutionary relationships among closely related organisms [72, 73].

The methods used for the isolation and generic identification of Acanthamoeba spp. have become standard. The validity of the identification of the 18 or more described species is somewhat more problematic and uncertain [74, 75]; however, species identification is essential for epidemiological studies [22]. The taxonomic classification of the members of the genus Acanthamoeba is based on morphological observations of the trophozoite and cyst forms $[59,76]$. This classification defines the genus clearly, but the variation in cyst morphology seen even within cultured strains makes the identification of many described species a subjective process [59]. Bogler and colleagues [77] consider that a single species in the genus can comprise a mixture of pathogenic and non-pathogenic strains, and that problems of identification and determination of pathogenicity are compounded by attenuation of virulence during laboratory culture. Pathogenicity is probably opportunist and it is possible that all strains have a pathogenic potential, but this is uncertain and it is equally possible that pathogenic and non-pathogenic strains are equivalent to distinct species [77]. Further investigations by several methods are needed for the differentiation of acanthamoebae. Restriction endonuclease digestion of whole-cell DNA $[5,59,77]$ or mtDNA $[5,6,21,22,59,77]$, and iso-enzyme electrophoresis [58, 59] have proved most useful in this respect. Inter-strain variations within species, similarities between strains of separate species, and inadequacies of the present taxonomic classification of the acanthamoebae have been demonstrated by these methods [59].

\section{Restriction endonuclease digestion of whole-cell DNA}

The conventional method for diagnosis of Acanthamoeba keratitis is by culture of the corneal biopsy material on non-nutrient agar seeded with a lawn of Escherichia coli (NNA-E. coli) [6, 27]. Acanthamoeba spp. can be identified readily by the morphological appearance of the trophozoite and cyst forms $[6,21$, $27,76]$. The trophozoites can be adapted to axenic (bacteria-free) growth in liquid media. Differentiation can be achieved by restriction endonuclease digestion of whole-cell DNA to detect RFLPs following agarose gel electrophoresis [5]. This technique is highly specific for differentiating morphologically identical Acanthamoeba strains isolated from keratitis cases and the environment. Kilvington et al. [5] demonstrated that isolates from a patient's cornea, contact lens container, saline rinsing solution and kitchen coldwater tap shared identical RFLPs; thus, the study implicated, for the first time, domestic tap water as the source of Acanthamoeba in keratitis [5].

The relationship between 33 morphologically identical Acanthamoeba isolates ( 30 isolates from patients with keratitis, two isolates from contact lens storage containers and one isolate from soil) was investigated by restriction endonuclease digestion of whole-cell DNA by Kilvington et al. [59]. The 33 strains formed cysts typical of group II Acanthamoeba spp. and resembled A. polyphaga, or possibly A. castellanii [78]. Restriction endonuclease digestion of Acanthamoeba wholecell DNA and RFLPs differentiated these isolates into seven multiple-isolate and three single-isolate groups following analysis on agarose gels. In the largest group, containing nine isolates, eight isolates were from keratitis cases in various locations. This group may, therefore, indicate the type most frequently associated with keratitis. In this study, of three consecutive isolates from the same patient over a 7month period, only one was resistant to chemotherapeutic agents, while the other two were susceptible. As all three isolates showed identical RFLPs, this result indicates that resistance was acquired by the original infecting strain during therapy [59].

RFLP profiles may also be useful in identifying pathogenic Acanthamoeba strains. The virulence of acanthamoebae has been shown to attenuate during axenic culture [79] and may account for the description of both pathogenic and non-pathogenic strains within the same species [80].

It appears that restriction endonuclease digestion of whole-cell DNA is a potent technique for differentiating morphologically identical Acanthamoeba strains by the detection of mtDNA RFLPs. However, 
presently, it is unclear whether Acanthamoeba mtDNA RFLPs indicate intra- or inter-species differences [59].

\section{Restriction endonuclease digestion of $m t D N A$}

The method is based on electrophoresis of DNA fragments obtained by restriction enzyme digestion of mtDNA. It has been used to study the intra- and interspecies relationships in a variety of organisms. This type of analysis has proved useful in clarifying phylogenetic relationships among closely related organisms $[21,72,73]$.

Bogler et al. [77] tested this approach with amoebae by examining the relationships among 15 strains from four species; pathogenic and non-pathogenic strains were included in the study [77]. DNA fragment size polymorphisms were used to estimate nucleotide sequence polymorphisms, in the expectation that the latter would correlate with the overall genetic relatedness of the various strains [81]. Ten distinct families of electrophoretic patterns (digestion genotypes) were observed [77]. Seven genotypes were found for seven strains considered non-pathogenic or of unknown pathogenicity. Three genotypes were associated with pathogenic strains. One of these genotypes included a single pathogenic strain, a second included one pathogen and one strain of unknown pathogenicity, and the third included five pathogenic strains. The latter five strains were of widespread geographical origin and had been assigned previously to two different species. The results suggested that extensive nucleotide sequence diversity occurs among strains from a single species of Acanthamoeba, but that subgroups of strains with similar sequences also occur. Thus, restriction enzyme analysis can identify clusters of strains and may be a useful approach to classification in the genus. However, it is clear that pathogenicity is not associated with a single subgroup. Bogler et al. concluded that improvements in classification should help clarify relationships among pathogenic and non-pathogenic strains [77].

Yagita and Endo [21] used RFLP analysis to type Acanthamoeba isolates from human eye infections, contact lens containers and soil in Japan. Four distinct mtDNA RFLP genotypes were discovered for eight strains. The discovery of four distinct RFLP genotypes for various strains of A. castellanii is evidence for DNA sequence diversity within a species [21, 77]. Three strains of $A$. polyphaga from different sources and one strain of $A$. castellanii shared one RFLP genotype identical to the RFLP genotype of the Ma strain of A. castellanii. Although there might be an argument about the morphological classification reported by Yagita and Endo, the results cannot be attributed simply to the difficulties in distinguishing these species of amoeba. Assuming that mtDNA in Acanthamoeba behaves similarly to that in other organisms, i.e., as a clonal molecule, it would not be surprising to find most of the variability in $A$. castellanii and very little in A. polyphaga. This would be particularly so if $A$. polyphaga had diverged from $A$. castellanii recently [21]. Similar results have been observed in man [82], mice [83] and fungi [84].

Bogler et al. [77] noted the close relationship between mtDNA of the Ma and Castellani strains; the Ma strain was isolated from human eye infection and the Castellani strain from yeast culture. Consequently, they highlighted the need to test the pathogenicity of the Castellani strain, which is the type strain for $A$. castellanii. One of the strains from a human eye infection had an RFLP pattern identical to that of the Castellani strain. In addition, the mtDNA genotype of a strain isolated from a patient's contact lens container, identified as A. polyphaga, was identical to the pathogenic Ma strain and was also found among various other isolates. Based on the above, the mtDNA genotypes may be a useful aid in the taxonomy of free-living amoeba species and in the recognition of the pathogenic potential [21].

Few epidemiological studies have included environmental isolates originating from the same geographical area in which the clinical cases occurred. Gautom et al. [22] undertook an investigation to determine the usefulness of mtDNA fingerprinting as an epidemiological tool for identifying potential reservoirs of infection. The inclusion of environmental isolates demonstrated that the most common clinical isolates do have counterparts that are isolated readily from the surrounding environment, and that some of these counterparts appear to be geographically widespread. This study confirmed the usefulness of mtDNA fingerprinting in the analysis of Acanthamoeba epidemiology and systematics [22].

\section{Iso-enzyme pattern analysis}

For the specific identification of the water-soluble protein extracts of an axenically growing Acanthamoe$b a$ isolate (obtained from a patient with keratitis), Matias et al. [58] subjected the extracts to iso-enzyme studies. Iso-electric focusing was performed by PAGE with a $\mathrm{pH}$ gradient $3-10$. The iso-enzymes investigated included acid phosphatase (AP), glucose-6-phosphate dehydrogenase (G-6-PDH), $\beta$-hydroxybutyric dehydrogenase $(\beta-\mathrm{HBDH})$, alcohol dehydrogenase $(\mathrm{ADH})$ and esterase. Based on the iso-enzyme patterns for G-6$\mathrm{PDH}, \beta-\mathrm{HBDH}, \mathrm{ADH}$ and esterase, the isolate was related more closely to $A$. quina-A. lugdunensis than to other Acanthamoeba spp. This apparent close relationship to $A$. quina-A. lugdunensis, coupled with the lethality of the former in BALB/c mice, underlined the potential pathogenicity of this isolate [58]. Kong et al. [85] observed inter-strain polymorphisms of isoenzyme profiles and mtDNA fingerprints among seven strains of Acanthamoeba isolated from different sources and assigned morphologically to A. polyphaga. 
The inter-strain polymorphisms for AP, lactate dehydrogenase and G-6-PDH were associated with similarity for glucose phosphate isomerase, leucine aminopeptidase and malate dehydrogenase. Daggett et al. [86] also used iso-enzyme electrophoresis of three different enzyme systems to compare 71 strains assigned to the 15 Acanthamoeba spp. that are recognised currently. A phylogenetic (cladistic) analysis of the zymograms arranged the strains in 15 distinguishable lineages, not all of which corresponded to current taxonomic assignments. The analysis also made it possible to place strains which had been identified previously only to the genus level. Therefore, these results suggest that previous criteria used to classify Acanthamoeba are not adequate for fully resolving taxa to the species level [86].

\section{Naturally occurring bacterial endosymbionts}

The presence of endosymbionts has been demonstrated in many protozoan species $[57,87-90]$. The symbionts may either occur 'naturally' or may represent more recently phagocytosed organisms that have adapted to the intracellular environment. Phagocytosed bacteria may grow and reproduce within the protozoan host and, in some cases, have been shown to eventually become symbionts [91]. The process itself, and its pathogenic significance, is not well known; hardly any data can be found on the mechanism by which it develops and by which it supports or at least allows the survival of both organisms.

Small, free-living amoebae such as Naegleria and Acanthamoeba have been found to have bacterial endosymbionts [87, 88]; indeed, Fritsche and Gautom $[57,89]$ have suggested that endosymbiosis occurs commonly among members of the family Acanthamoebidae. Several studies have speculated that endosymbionts are potential virulence factors [87, 89, 90]. Fritsche et al. [57] demonstrated intracellular bacteria in $24 \%$ of axenically grown Acanthamoeba isolates. These micro-organisms were gram-negative and non-acid fast. They could not be cultured by routine methodologies, although electron microscopy revealed multiplication within the amoebic cytoplasm. Examination for Legionella spp. with culture and nucleic acid probes was unsuccessful. The bacteria appear to be endosymbionts that multiply within their amoebic hosts. Rod-shaped bacteria were identified in five of 23 clinical Acanthamoeba isolates, four of 25 environmental isolates, and two of nine Acanthamoeba isolates from the ATCC that were previously unrecognised as having endosymbionts. Coccus-shaped bacteria were also present in one clinical isolate and two environmental isolates. No statistical difference was found between the numbers of endosymbiont strains originating from clinical and environmental amoebic isolates. They were found in different geographical areas, demonstrating their widespread occurrence in nature. These findings suggest that endosymbiosis occurs commonly among members of the family Acanthamoebidae. The role of such endosymbionts in pathogenesis remains unknown, but they have been implicated in the development of amoebic keratitis [57].

Experimental transmission of two bacterial endosymbionts to symbiont-free isolates of Acanthamoeba spp. was studied by Gautom and Fritsche [89] to determine the specificity of the host-symbiont relationship. Both symbionts originated from amoebic isolates displaying an identical mtDNA EcoRI fingerprint. Symbiosis was established easily in one amoebic isolate with a homologous mtDNA fingerprint. Exposure of a heterologous amoebic isolate to the two symbionts resulted in cell death without the establishment of symbiosis. These studies suggest that there is a specific recognition system between particular isolates of Acanthamoeba and their symbionts, and that the appearance of a killer phenotype is related to contact between mismatched, although recognised, pairs.

Since the first report by Rowbotham [92], the association of the amoebae Naegleria and Acanthamoeba with the symbiont Legionella pneumophila, the causative agent of Legionnaires' disease, has been a subject of interest [91, 93]. Acanthamoeba, Naegleria, Hartmannella, Vahlkampfia and Echinamoeba have been shown to support the growth of legionellas [94], and environmental growth of legionellas in the absence of protozoa has not been documented. It is thought likely that the protozoa are the primary means of proliferation of these bacteria under natural conditions $[95,96]$. This inter-relationship within the ecosystem can modify the virulence of Legionella [97]; it may also be involved in the observed phenomenon that $L$. pneumophila can be viable but non-detectable by cultivation on BCYE agar-based systems [98]. Hay et al. have proposed that the latter observation may have profound implications with regard to surveillance of water systems for Legionella [99], especially with respect to prevention of outbreaks of nosocomial Legionnaires' disease [100].

\section{Isolation and identification of $N$. fowleri and Acanthamoeba in Hungary}

Cases of PAM have been described in many countries, but no confirmed cases have been reported in Hungary. However, until recently, no trials had been performed to investigate the occurrence and possible pathogenic significance of 'free-living' amoebae. If $N$. fowleri was isolated, $N$. fowleri might then be considered as a possible causative agent when cases of meningoencephalitis are diagnosed in Hungary.

Naegleria spp. are found invariably in warm waters, at temperatures up to $45^{\circ} \mathrm{C}$. Therefore, it seemed worth- 
while to investigate geothermal pools for pathogenic $N$. fowleri. Thus, in 1994, a systematic study was started in Hungary to analyse the amoebic fauna of some natural and geothermal waters, as well as swimming pools and bathing pools fed by natural (geothermal) water [6, 27]. The results obtained are summarised in Table 1. Of particular interest was a thermotolerant Naegleria spp. found in a Szeged swimming pool fed by geothermal water and containing chlorine for disinfection. This isolate did not adapt to axenic growth in serum-casein-glucose-yeast-extract-medium (SCGYEM) as easily as reported previously for other Naegleria spp. [19, 67]. However, the iso-enzyme profile of this Naegleria isolate growing axenically was highly similar to that of an $N$. philippinarum (tentative name) isolate from the brain aspirate of a 12-year-old boy with PAM in Manila (unpublished results). This finding supports a role as a possible human pathogen for the Naegleria isolate from Szeged, Hungary. The pathogenicity of this isolate in mice is the subject of current investigations although, according to Griffin [34], temperature tests may prove more useful than virulence tests in mice in identifying Naegleria which are pathogenic for man. The strains of mice generally used are selected to be susceptible, but differ considerably in their degree of susceptibility [101, 102]. As an example, amoeba strains $\mathrm{HN}-3$ and $\mathrm{A} 5$ of Culbertson both killed the mice used by Singh and Das, whereas only strain HN-3 killed the mice used by Culbertson et al. [101, 102].

In this Department, $A$. castellanii was isolated from the cerebrospinal fluid (CSF) of a 15-year-old girl with lymphocytic meningoencephalitis [14]. In addition to the meningeal excitation symptoms, the clinical picture included focal neurological changes as well as alterations in the electroencephalogram. Negative results in bacteriological and virological examinations and the inefficiency of the initial therapy raised the possibility of protozoal infection. Following repeated laboratory examinations, the presence of $A$. castellanii in the CSF was demonstrated. Also in this Department, A. polyphaga was isolated from the contact lens storage solution of a patient with corneal ulcer [7].

The growing use of contact lenses increases the number of persons at risk of Acanthamoeba keratitis. This is an important aspect in Hungary where, because of some special economic circumstances, there has been a rapid expansion of contact lens usage since 1990. Acanthamoeba spp. (strain Cl) has been isolated from a commercial contact lens cleaning and disinfecting solution, from the corneal scrapings of a patient with severe eye soreness, and from the environment (strains Mo and Dun) [6, 27]. Morphologically, the human isolate $(\mathrm{Cl})$ was indistinguishable from the Acanthamoeba strains isolated from a moss (Mo) or from the River Danube (Dun) (Fig. 1) [6, 27]. When RFLP analysis [21] was used to compare these isolates with human isolates from other countries [6], the RFLP phenotype of strain $\mathrm{Cl}$ was similar to that of strain JAC/E4 from six different countries [21]. Strain Dun was comparable to strain Ma from nine countries, and strain Mo was comparable to strain NZAU from New Zealand [21]. Thus, RFLP analysis of mtDNA may be a useful tool for the taxonomic classification

Table 1. Free-living amoebae isolated from sources in Hungary during the survey period 23 Sept. 1994-14 Oct. 1994

\begin{tabular}{|c|c|c|c|c|c|c|c|c|}
\hline Source & Acanthamoeba & Hartmannella & $\begin{array}{l}\text { Vahlkampfiid } \\
\text { amoeba }\end{array}$ & Vannella & Vexillifera & Cochliopodia & Filamoeba & $\begin{array}{l}\text { Non-cyst- } \\
\text { forming } \\
\text { amoeba }\end{array}$ \\
\hline \multicolumn{9}{|l|}{ Szeged } \\
\hline Pond Vér & $\ldots$ & $\ldots$ & $\ldots$ & + & $\ldots$ & & $\ldots$ & $\ldots$ \\
\hline Pond Sziksós & $\ldots$ & + & $\ldots$ & + & $\ldots$ & $\ldots$ & $\ldots$ & $\ldots$ \\
\hline River Tisza & $\ldots$ & + & $\ldots$ & $\ldots$ & $\ldots$ & $\ldots$ & $\ldots$ & $\ldots$ \\
\hline \multicolumn{9}{|l|}{ Budapest } \\
\hline $\begin{array}{r}\text { River Duna } \\
\text { Balatongyörök }\end{array}$ & + & $\ldots$ & $\ldots$ & $\ldots$ & $\ldots$ & $\ldots$ & $\cdots$ & $\cdots$ \\
\hline $\begin{array}{l}\text { Lake Balaton } \\
\text { Keszthely }\end{array}$ & $\cdots$ & $\cdots$ & $\cdots$ & + & $\cdots$ & $\cdots$ & $\cdots$ & $\cdots$ \\
\hline $\begin{array}{l}\text { Lake Balaton } \\
\text { Hévíz }\end{array}$ & $\ldots$ & + & $\ldots$ & + & + & $\ldots$ & $\ldots$ & $\ldots$ \\
\hline $\begin{array}{l}\text { Hot spring pond } \\
\text { Szeged }\end{array}$ & $\ldots$ & $\ldots$ & $\ldots$ & + & $\cdots$ & + & $\cdots$ & $\cdots$ \\
\hline $\begin{array}{l}\text { Anna spring } \\
\text { Drinking basin } \\
\text { Bath tub water }\end{array}$ & + & + & $\ldots$ & $\ldots$ & $\ldots$ & $\ldots$ & + & $\ldots$ \\
\hline $30^{\circ} \mathrm{C}$ & $\ldots$ & $\ldots$ & $\cdots$ & $\ldots$ & $\ldots$ & $\ldots$ & $\ldots$ & + \\
\hline $36^{\circ} \mathrm{C}$ & $\ldots$ & + & $+*$ & $\ldots$ & $\ldots$ & $\cdots$ & $\cdots$ & $\ldots$ \\
\hline $40^{\circ} \mathrm{C}$ & $\ldots$ & + & $\cdots$ & .. & $\cdots$ & $\cdots$ & $\ldots$ & $\cdots$ \\
\hline Swimming pool & $\cdots$ & $\cdots$ & $+^{\dagger}$ & $\cdots$ & $\cdots$ & $\cdots$ & $\cdots$ & $\cdots$ \\
\hline Moss & + & $\ldots$ & $\cdots$ & $\ldots$ & $\ldots$ & $\ldots$ & $\ldots$ & $\ldots$ \\
\hline Soil & $\ldots$ & $\cdots$ & $\cdots$ & $\cdots$ & $\cdots$ & $\cdots$ & $\cdots$ & + \\
\hline Human corneal scraping & + & $\ldots$ & $\ldots$ & $\ldots$ & $\ldots$ & $\ldots$ & $\ldots$ & $\ldots$ \\
\hline
\end{tabular}

\footnotetext{
* Willertia magna.
}

${ }^{\dagger}$ Naegleria spp. 

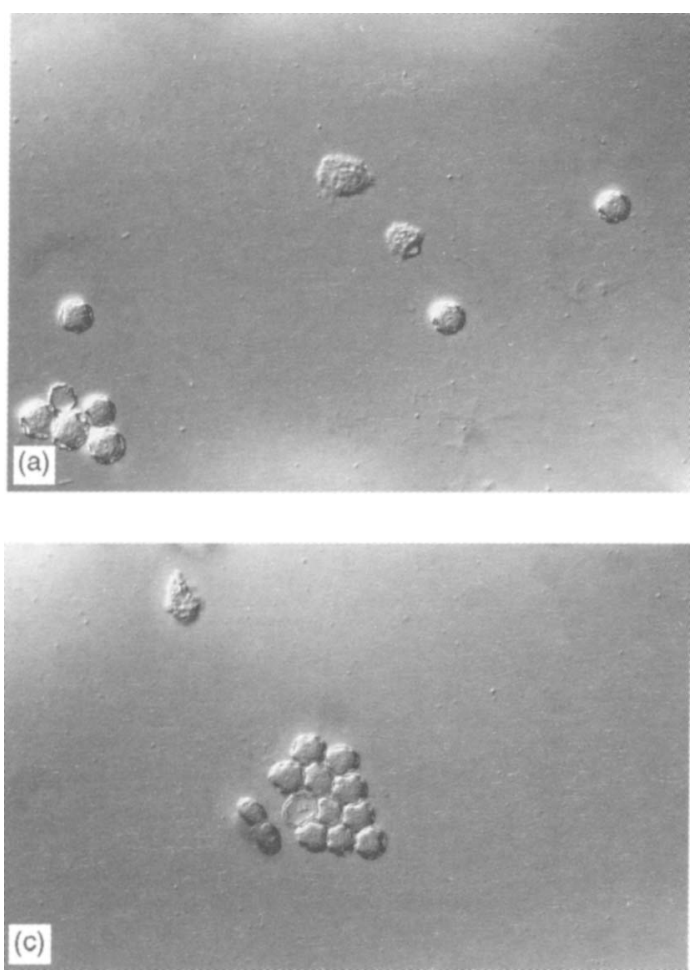

of free-living amoeba species, and perhaps also for the determination of their pathogenic potential.

A further interesting observation identified intracellular bacteria in an axenically grown Acanthamoeba spp. isolated from the basin of a natural hot-water



Fig. 1. Morphological features of the cysts and vegetative forms of three Hungarian Acanthamoeba isolates: a, strain $\mathrm{Cl}$; b, strain $\mathrm{Mo}$; c, strain Dun. All three strains belong to group II of Pussard and Pons [78], but are virtually indistinguishable by morphological features.

spring [6]. Electron microscopy revealed evidence for multiplication of rod-shaped bacteria within the amoebic cytoplasm (Fig. 2). The possible role of the endosymbiont in any pathogenic process is unknown, but its identification and characterisation is the subject of further investigations.

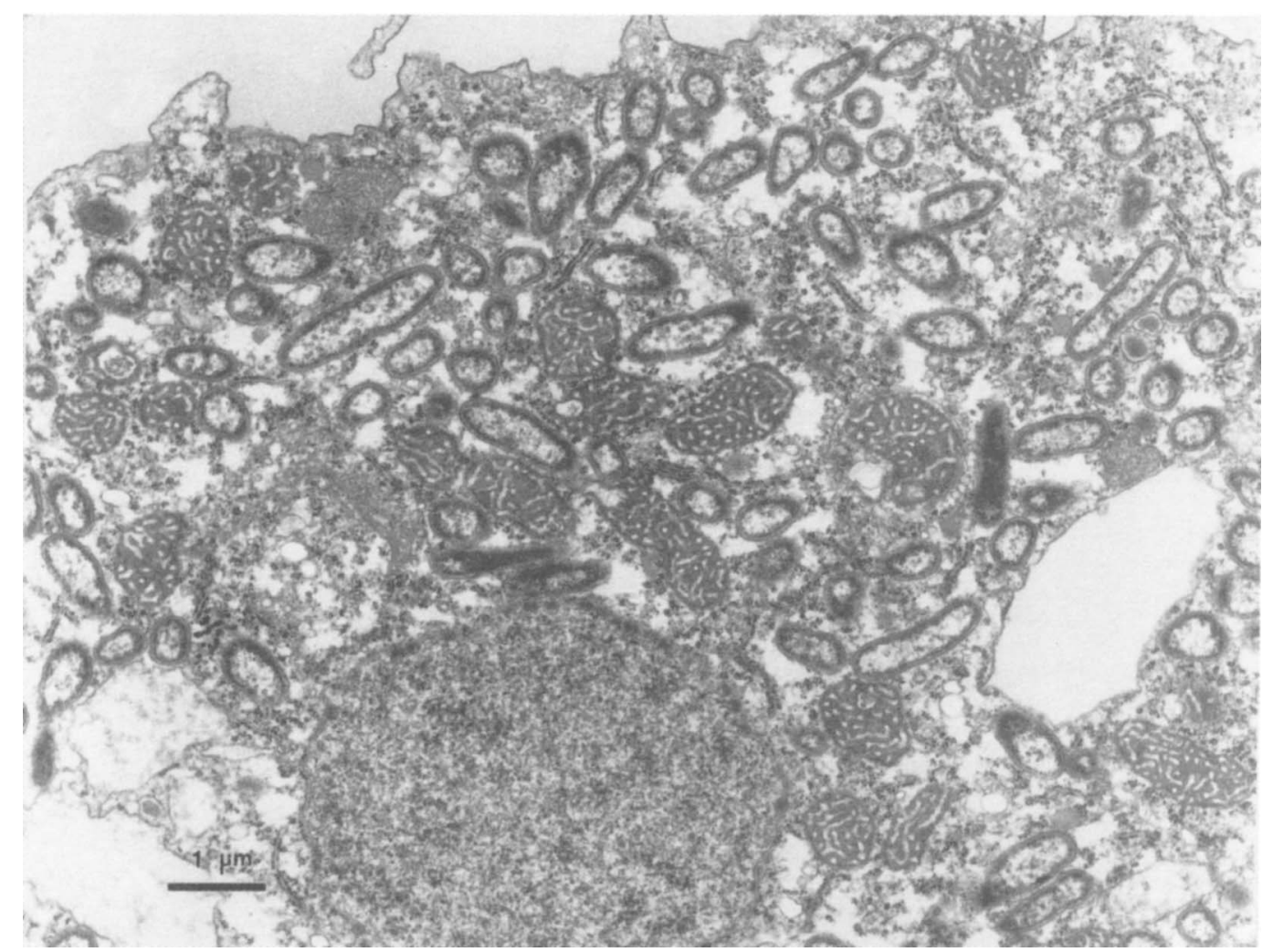

Fig. 2. Intracellular bacteria observed in an axenically grown Acanthamoeba spp. isolated from the basin of a natural hot-water spring. 


\section{Conclusions}

'Free-living' amoebae can be found worldwide, under practically every kind of living conditions. Some (e.g., Naegleria and Acanthamoeba) are opportunist human parasites. Their pathogenic role is far more important than was thought previously. Since the first report in 1965 by Fowler and Carter [32], many lethal cases of PAM caused by Naegleria have been reported. In addition, a significant percentage of cases of keratitis and corneal ulcers in wearers of contact lenses, as well as many cases of swimming pool conjunctivitis (and some diseases of other organs), have been proved to be evoked by Acanthamoeba. Precise differentiation and identification of the pathogenic and non-pathogenic species and strains would be of primary importance from a therapeutic point of view. However, morphological markers, survival in different temperatures, $\mathrm{pH}$ dependency and virulence in infected animals (mice), all fail to fulfil the requirements for specificity, sensitivity and reliability. The newer molecular methods, such as restriction endonuclease digestion of whole-cell DNA, restriction endonuclease digestion of mtDNA, agarose iso-electric focusing and staining for acid phosphatase and propionyl esterase activity, and immunological analysis of fine differences by MAbs, have produced promising results with respect to the identification of species and strains, with special reference to their human pathogenicity, but quicker and more reliable methods would still be desirable in view of the clinical significance of the problem. The significance of the phenomenon of endosymbiosis is still practically unknown. A systematic, detailed analytic survey in Hungary for the isolation and identification of 'free-living' amoebae has isolated possibly pathogenic strains of Naegleria and Acanthamoeba, and has observed cases of endosymbiosis.

The generous support of the Hungarian-Japanese S\&T Cooperation throughout this work is acknowledged.

\section{References}

1. Page FC. Rosculus ithacus Hawes, 1963 (Amoebida, Flabelluidae) and the amphizoic tendency in amoebae. Acta Protozool 1974; 13: 143-154.

2. Daggett P-M, Sawyer TK, Nerad TA. Distribution and possible interrelationships of pathogenic and nonpathogenic Acanthamoeba from aquatic environments. Microb Ecol 1982; 8: $371-386$.

3. Stevens AR, Tyndall RL, Coutant CC, Willaert E. Isolation of the etiological agent of primary amoebic meningoencephalitis from artificially heated waters. Appl Environ Microbiol 1977; 34: $701-705$.

4. Sison JP, Kemper CA, Loveless M, McShane D, Visvesvara GS, Deresinksi SC. Disseminated Acanthamoeba infection in patients with AIDS: case reports and review. Clin Infect Dis 1995; 20: $1207-1216$.

5. Kilvington S, Larkin DFP, White DG, Beeching JR. Laboratory investigation of Acanthamoeba keratitis. J Clin Microbiol 1990; 28: 2722-2725.

6. Szénási Z, Endo T, Yagita $\mathrm{K}$, Urbán $\mathrm{E}$, Végh $\mathrm{M}$, Nagy $\mathrm{E}$. Isolation and restriction enzyme analysis of mitochondrial DNA (mtDNA) of Hungarian Acanthamoeba isolates from human eye infection and from the environment. Parasitol Hung 1995; 28: 5-12.

7. Végh M, Nagy E, Matyi A. Hornhautulkus bei weichen Kontaktlinsen. Contactologia 1988; 4: 194-195.

8. Illingworth CD, Cook SD, Karabatsas CH, Easty DL Acanthamoeba keratitis: risk factors and outcome. $\mathrm{Br} J$ Ophthalmol 1995; 79: 1078-1082.

9. D'Aversa G, Stern GA, Driebe WT. Diagnosis and successful medical treatment of Acanthamoeba keratitis. Arch Ophthalmol 1995; 113: 1120-1123.

10. Radford CF, Bacon AS, Dart JKG, Minassian DC. Risk factors for acanthamoeba keratitis in contact lens users: a case-control study. $B M J$ 1995; 310: 1567-1570.

11. Chatterjee A, Kwartz J, Ridgway AEA, Storey JK. Disposable soft contact lens ulcers: a study of 43 cases seen at Manchester Royal Eye Hospital. Cornea 1995; 14: 138-141.

12. Bacon AS, Frazer DG, Dart JKG, Matheson M, Ficker LA, Wright P. A review of 72 consecutive cases of Acanthamoeba keratitis, 1984-1992. Eye 1993; 7: 719-725.

13. Gray TB, Cursons RTM, Sherwan JF, Rose PR. Acanthamoe$b a$, bacterial, and fungal contamination of contact lens storage cases. Br J Ophthalmol 1995; 79: 601-605.

14. Matyi A, Somogyi I, Deák J, Nagy E, Földes J. Acanthamoeba castellanii által okozott meningoencephalitis magyarországi elöfordulása (Meningoencephalitis caused by Acanthamoeba castellanii in Hungary). Orv Hetil 1985 126: $2541-2544$.

15. Larkin DFP, Easty DL. External eye flora as a nutrient source for Acanthamoeba. Graefes Arch Clin Exp Ophthalmol 1990 228: $458-460$

16. Sykora JL, Keleti G, Martinez AJ. Occurrence and pathogenicity of Naegleria fowleri in artifically heated waters. Appl Environ Microbiol 1983; 45: 974-979.

17. De Jonckheere JF, Yagita K, Endo T. Restriction-fragmentlength polymorphism and variation in electrophoretic karyotype in Naegleria fowleri from Japan. Parasitol Res 1992; 78: $475-478$.

18. De Jonckheere JF. Geographic origin and spread of pathogenic Naegleria fowleri deduced from restriction enzyme patterns of repeated DNA. Biosystems 1988; 21: 269-275.

19. De Jonckheere JF, Yagita K, Kuroki T, Endo T. First isolation of pathogenic Naegleria fowleri in Japan. Jpn $J$ Parasitol 1991; 40: 352-357.

20. Sparagano O, Drouet E, Brebant R, Manet E, Denoyel G-A, Pernin $P$. Use of monoclonal antibodies to distinguish pathogenic Naegleria fowleri (cysts, trophozoites, or flagellate forms) from other Naegleria species. J Clin Microbiol 1993; 31: $2758-2763$

21. Yagita K, Endo T. Restriction enzyme analysis of mitochondrial DNA of Acanthamoeba strains in Japan. $J$ Protozool 1990; 37: 570-575.

22. Gautom RK, Lory S, Seyedirashti S, Bergeron D, Fritsche T Mitochondrial DNA fingerprinting of Acanthamoeba spp. isolated from clinical and environmental sources. $J$ Clin Microbiol 1994; 32: 1070-1073.

23. Badenoch PR, Adams $M$, Coster DJ. Corneal virulence cytopathic effect on human keratocytes and genetic characterization of Acanthamoeba. Int J Parasitol 1995; 25: 229239.

24. Bogler SA, Zarley CD, Burianek LL, Fuerst PA, Byers TJ. Interstrain mitochondrial DNA polymorphism detected in Acanthamoeba by restriction endonuclease analysis. $\mathrm{Mol}$ Biochem Parasitol 1983; 8: 145-163.

25. Byers TJ, Bogler SA, Burianek LL. Analysis of mitchondrial DNA variation as an approach to systematic relationships in the genus Acanthamoeba. J Protozool 1983; 30: 198-203.

26. Byers TJ, Hugo ER, Stewart VJ. Genes of Acanthamoeba DNA, RNA and protein sequences (a review). J Protozool 1990; 37: $17 \mathrm{~s}-25 \mathrm{~s}$.

27. Urbán E, Szénási Z, Végh M, Endo T, Yagita K, Nagy E. Isolation of Acanthamoeba spp from human sample and from the environment. Clin Exp Lab Med 1995; 22: 248-252.

28. Martinez AJ (ed). Free-living amebas: natural history, prevention, diagnosis, pathology, and treatment of disease. Boca Raton, CRC Press. 1985.

29. Huizinga HW, McLaughlin GL. Thermal ecology of Naegle ria fowleri from a power plant cooling reservoir. Appl Environ Microbiol 1990; 56: 2200-2205.

30. Martínez AJ, Guerra AE, García-Tamayo J, Cespedes G, 
Gonzalez Alfonzo JE, Visvesvara GS. Granulomatous amebic encephalitis: a review and report of a spontaneous case from Venezuela. Acta Neuropathol 1994; 87: 430-434.

31. Flores BM, Garcia CA, Stamm WE, Torian BE. Differentiation of Naegleria fowleri from Acanthamoeba species by using monoclonal antibodies and flow cytometry. $J$ Clin Microbiol 1990; 28: 1999-2005.

32. Fowler M, Carter RF. Acute pyogenic meningitis probably due to Acanthamoeba sp.: a preliminary report. $B M J 1965 ; 2$ : $740-742$.

33. Tyndall RL, Ironside KS, Metler PL, Tan EL, Hazen TC, Eliermans CB. Effect of thermal additions on the density and distribution of thermophilic amoebae and pathogenic Naegleria fowleri in a newly created cooling lake. Appl Environ Microbiol 1989; 55: 722-732.

34. Griffin JL. Temperature tolerance of pathogenic and nonpathogenic free-living amoebas. Science 1972; 178: 869-870.

35. De Jonckheere J, Voorde H. The distribution of Naegleria fowleri in man-made thermal waters. Am J Trop Med Hyg 1977; 26: 10-15.

36. Duma RJ (ed). Study of pathogenic free-living amebas in fresh-water lakes in Virginia. US Environmental Protection Agency Publication No. EPA-600/S1-80-0-037. Washington, DC, Environmental Protection Agency. 1980

37. Fliermans CB, Tyndall RL, Domingue EL, Willaert EJP. Isolation of Naegleria fowleri from artificially heated waters. $J$ Therm Biol 1979; 4: 303-305.

38. Wellings FM, Amuso PT, Chang SL, Lewis AL. Isolation and identification of pathogenic Naegleria from Florida lakes. Appl Environ Microbiol 1977; 34: 661-667.

39. De Jonckheere J, Van Dijck P, van de Voorde H. The effect of the thermal pollution on the distribution of Naegleria fowleri. J Hyg 1975; 75: 7-13.

40. Shapiro MA, Karol MH, Keleti G, Sykora JL, Martinez AJ. The role of free living amoebae occurring in heated effluents as causative agents of human disease. In: Proceedings of International Conference on Coal Fired Power Plants and Aquatic Environment. Copenhagen, Water Quality Institute, 1982: 99-111.

41. Wellings FM, Amuso PT, Lewis AL et al. Pathogenic Naegleria, distribution in nature. Report No. EPA-600/1-79018. Cincinnati, US Environmental Protection Agency. 1979.

42. Rondanelli EG (ed). Infectious diseases 1. Amphizoic amoebae human pathology. Padua, Piccin Nuova Libraria. 1987.

43. De Jonckheere JF. Characterization of Naegleria species by restriction endonuclease digestion of whole-cell DNA. Mol Biochem Parasitol 1987; 24: 55-66.

44. McLaughlin GL, Brandt FH, Visvesvara GS. Restriction fragment length polymorphisms of the DNA of selected Naegleria and Acanthamoeba amoebae. J Clin Microbiol 1988; 26: 1655-1658.

45. De Jonckheere JF. Isoenzyme patterns of pathogenic and nonpathogenic Naegleria spp. using agarose isoelectric focusing. Ann Microbiol 1982; 133: 319-342.

46. Visvesvara GS, Peralta MJ, Brandt FH, Wilson M, Aloisio C, Franko E. Production of monoclonal antibodies to Naegleria fowleri, agent of primary amebic meningoencephalitis. J Clin Microbiol 1987; 25: 1629-1634

47. Sawyer TK, Visvesvara GS, Harke BA. Pathogenic amoebas from brackish and ocean sediments, with a description of Acanthamoeba hatchetti, n. sp. Science 1977; 196: 13241325 .

48. Brown TJ, Cursons RTM, Keys FA. Amoebae from antarctic soil and water. Appl Environ Microbiol 1982; 44: 491-493.

49. Franke ED, Mackiewicz JS. Isolation of Acanthamoeba and Naegleria from the intestinal contents of freshwater fishes and their potential pathogenicity. $J$ Parasitol 1982; 68: 164-166.

50. Kyle DE, Noblet GP. Seasonal distribution of thermotolerant free-living amoebae. I. Willard's Pond. J Protozool 1986; 33: $422-434$.

51. Wiens JJ, Jackson WB. Acanthamoeba keratitis: an update. Can J Ophthalmol 1988; 23: 107-110.

52. Hseih WC, Dornic DI. Acanthamoeba dendriform keratitis. $J$ Am Optom Assoc 1989; 60: 32-34.

53. Rivasi $\mathrm{F}$, Longanesi $\mathrm{L}$, Casolari $\mathrm{C}$ et al. Cytologic diagnosis of Acanthamoeba keratitis. Report of a case with correlative study with indirect immunofluorescence and scanning electron microscopy. Acta Cytol 1995; 39: 821-826.
54. Stehr-Green JK, Bailey TM, Visvesvara GS. The epidemiology of Acanthamoeba keratitis in the United States. Am J Ophthalmol 1989; 107: 331-336.

55. Berger ST, Mondino BJ, Hoft RH et al. Successful medical management of Acanthamoeba keratitis. Am $J$ Ophthalmo 1990; 110: 395-403.

56. Driebe WT, Stern GA, Epstein RJ, Visvesvara GS, Adi M, Komadina T. Acanthamoebic keratitis. Potential role for topical clotrimazole in combination chemotherapy. Arch Ophthalmol 1988; 106: 1196-1201.

57. Fritsche TR, Gautom RK, Seyedirashti S, Bergeron DL, Lindquist TD. Occurrence of bacterial endosymbionts in Acanthamoeba spp. isolated from corneal and environmental specimens and contact lenses. J Clin Microbiol 1993; 31: 1122-1126.

58. Matias R, Schottelius J, Raddatz CF, Michel R. Species identification and characterization of an Acanthamoeba strain from human cornea. Parasitol Res 1991; 77: 469-474.

59. Kilvington S, Beeching JR, White DG. Differentiation of Acanthamoeba strains from infected corneas and the environment by using restriction endonuclease digestion of wholecell DNA. J Clin Microbiol 1991; 29: 310-314.

60. van Klink F, Taylor WM, Alizadeh H, Jager MJ, van Rooijen N, Niederkorn JY. The role of macrophages in Acanthamoeba keratitis. Invest Ophthalmol Vis Sci 1996; 37: 1271-1281.

61. Clinch TE, Palmon FE, Robinson MJ, Cohen EJ, Barron BA Laibson PR. Microbial keratitis in children. Am J Ophthalmol 1994; 117: 65-71.

62. Ficker LA, Kirkness C, Wright P. Prognosis for keratoplasty in Acanthamoeba keratitis. Ophthalmology 1993; 100: 105110 .

63. Cerva L. Amebic meningoencephalitis. In: Braude A (ed) Medical microbiology and infectious diseases. Philadelphia, Saunders. 1981: 1281 .

64. Rivera F, Medina F, Ramerez P, Alcocer J, Vilaclara G, Robles E. Pathogenic and free-living protozoa cultured from the nasopharyngeal and oral regions of dental patients. Environ Res 1984; 33: 428-440.

65. Lindquist TD, Sher NA, Doughman DJ. Clinical signs and medical therapy of early Acanthamoeba keratitis. Arch Ophthalmol 1988; 106: 73-77.

66. Brandt FH, Ware DA, Visvesvara GS. Viability of Acanthamoeba cysts in ophthalmic solution. Appl Environ Microbiol 1989; 55: 1144-1146.

67. De Jonckheere JF. Use of an axenic medium for differentiation between pathogenic and nonpathogenic Naegleria fowleri isolates. Appl Environ Microbiol 1977; 33: 751-757.

68. Anzil AP Rao C, Wrzolek MA, Visvesvara GS, Sher JH, Kozlowski PB. Amebic meningoencephalitis in a patient with AIDS caused by a newly recognized opportunistic pathogen, Leptomyxid ameba Arch Pathol Lab Med 1991; 115: 21-25.

69. Griffin JL. The pathogenic amoeboflagellate Naegleria fowleri: environmental isolations, competitors, ecological interactions, and the flagellate-empty habitat hypothesis. $J$ Protozool 1983; 30: 403-409.

70. Sykora JL, Keleti G, Martinez AJ. Occurrence and pathogenicity of Naegleria fowleri in artificially heated waters. Appl Environ Microbiol 1983; 45: 974-979.

71. Costas M, Edwards SW, Lloyd D, Griffiths AJ, Turner G. Restriction enzyme analysis of mitochondrial DNA of members of the genus Acanthamoeba as an aid in taxonomy. FEMS Microbiol Lett 1983; 17: 231-234.

72. Brown GG, Simpson MV. Intra- and interspecific variation of the mitochondrial genome in Rattus norvegicus and Rattus rattus: restriction enzyme analysis of variant mitochondrial DNA molecules and their evolutionary relationships. Genetics 1981; 97: 125-143.

73. Yonekawa H, Moriwaki $\mathrm{K}$, Gotoh $\mathrm{O}$ et al. Evolutionary relationships among five subspecies of Mus musculus based on restriction enzyme cleavage patterns of mitochondrial DNA. Genetics 1981; 98: 801-816.

74. Uberlaker JE. Acanthamoeba spp: "opportunistic pathogens." Trans Am Microsc Soc 1991; 110: 289-299.

75. Visvesvara GS. Classification of Acanthamoeba. Rev Infect Dis 1991; 13 Suppl 5: S369-S372.

76. Page FC (ed). A new key to freshwater and soil gymnamoebae: with instructions for culture. Ambleside, Freshwater Biological Association. 1988.

77. Bogler SA, Zarley CD, Burianek LL, Fuerst PA, Byers TJ. 
Interstrain mitochondrial DNA polymorphism detected in Acanthamoeba by restriction endonuclease analysis. Mol Biochem Parasitol 1983; 8: 145-163.

78. Pussard M, Pons R. Morphologie de la paroi kystique et taxonomie du genre Acanthamoeba (Protozoa, Amoebida). Protistologica 1977; 13: 557-598.

79. Stevens AR, O'Dell WD. In vitro growth and virulence of Acanthamoeba. J Parasitol 1974; 60: 884-885.

80. De Jonckheere JF. Growth characteristics, cytopathic effect in cell culture, and virulence in mice of 36 type strains belonging to 19 different Acanthamoeba spp. Appl Environ Microbiol 1980; 39: 681-685.

81. Byers TJ, Bogler SA, Burianek LL. Analysis of mitochondria DNA variation as an approach to systematic relationships in the genus Acanthamoeba. J Protozool 1983; 30: 198-203.

82. Wilson AC, Cann RL, Carr SM et al. Mitochondrial DNA and two perspectives on evolutionary genetics. Biol J Linn Soc 1985; 26: $375-400$.

83. Fort $\mathrm{P}$, Darlu P, Piechaczyk M, Jeanteur P, Thaler L. Clonal divergence of mitochondrial DNA versus populational evolution of nuclear genome. Evol Theory 1984; 7: 81-90.

84. Taylor JW, Natvig DO. Mitochondrial DNA and evolution of heterothallic and pseudohomothallic Neurospora species. Mycol Res 1989; 93: 257-272.

85. Kong $\mathrm{HH}$, Park JH, Chung DI. Interstrain polymorphisms of isoenzyme profiles and mitochondrial DNA fingerprints among seven strains assigned to Acanthamoeba polyphaga. Korean J Parasitol 1995; 33: 331-340.

86. Daggett PM, Lipscomb D, Sawyer TK, Nerad TA. A molecular approach to the phylogeny of Acanthamoeba. Biosystems 1985; 18: 399-405.

87. Hall J, Voelz H. Bacterial endosymbionts of Acanthamoeba sp. J Parasitol 1985; 71: 89-95.

88. Drozanski WJ. Sarcobium lyticum gen. nov., sp. nov., an obligate intracellular bacterial parasite of small free-living amoebae. Int J Syst Bacteriol 1991; 41: 82-87.

89. Gautom RK, Fritsche TR. Transmissibility of bacterial endosymbionts between isolates of Acanthamoeba spp. $J$ Eukaryot Microbiol 1995; 42: 452-456.

90. Michel R, Hauroder-Philippczyk B, Muller K-D, Weishaar I. Acanthamoeba from human mucosa infected with an obligate intracellular parasite. Eur J Protistol 1994; 30: 104-110.
91. Yagita K, Matias RR, Yasuda T, Natividad FF, Enriquez GL, Endo T. Acanthamoeba sp. from the Philippines: electron microscopy studies on naturally occurring bacterial symbionts. Parasitol Res 1995; 81: 98-102.

92. Rowbotham TJ. Preliminary report on the pathogenicity of Legionella pneumophila for freshwater and soil amoebae. $J$ Clin Pathol 1980; 33: 1179-1183.

93. Bozue JA, Johnson W. Interaction of Legionella pneumophila with Acanthamoeba castellanii: uptake by coiling phagocytosis and inhibition of phagosome-lysosome fusion. Infect Immun 1996; 64: 668-673.

94. Fields BS. Legionella and protozoa: interaction of a pathogen and its natural host. In: Barbaree JM, Breiman RF, Dufour AP (eds) Legionella current status and emerging perspectives. Washington, DC, American Society for Microbiology. 1993: 129.

95. Fields BS, Sanden GN, Barbaree JM et al. Intracellular multiplication of Legionella pneumophila in amoebae isolated from hospital hot water baths. Curr Microbiol 1989; 18: 131137.

96. Hay J, Seal DV, Billcliffe B, Freer JH. Non-culturable Legionella pneumophila associated with Acanthamoeba castellanii: detection of the bacterium using DNA amplification and hybridization. $J$ Appl Bacteriol 1995; 78: 61-65.

97. Dowling JN, Saha AK, Glew RH. Virulence factors of the family Legionellaceae. Microbiol Rev 1992; 56: 32-60.

98. Connor R, Hay J, Mead AJC, Seal DV Reversal of inhibitory effects of Acanthamoeba castellani lysate for Legionella pneumophila using catalase. J Microbiol Methods 1993; 18: $311-316$.

99. Hay J, Seal DV. Surveying for legionnaires' disease bacterium. Curr Opin Infect Dis 1994; 7: 479-483.

100. Hay J, Seal DV. Monitoring of hospital water supplies for Legionella. J Hosp Infect 1994; 26: 75-78.

101. Culbertson CG, Holmes DH, Overton WM. Hartmannella castellani (Acanthamoeba $\mathrm{sp}$ ): preliminary report on experimental chemotherapy. Am $J$ Clin Pathol 1965; 43: $361-364$.

102. Culbertson CG, Ensminger PW, Overton WM. Hartmannella (Acanthamoeba). Experimental chronic, granulomatous brain infections produced by new isolates of low virulence. $A m J$ Clin Pathol 1966; 46: 305-314 